\title{
The hidden web and the fentanyl problem: detection of ocfentanil as an adulterant
}

\section{in heroin}

Pol Quintana ${ }^{1,2}$, Mireia Ventura ${ }^{1,2} * \dagger$, Marc Grifell $^{1,2,3} \dagger$, Alvaro Palma $^{2,3}$, Liliana Galindo ${ }^{2,3}$, Iván

Fornís $^{1}$, Cristina Gil ${ }^{1}$, Xoán Carbón ${ }^{1}$, Fernando Caudevilla ${ }^{1}$, Magí Farré ${ }^{2,5,6}$, Marta Torrens ${ }^{2,3,4}$

${ }^{1}$ Energy Control, Associació Benestar i Desenvolupament, Barcelona, Spain.

${ }^{2}$ Hospital del Mar Medical Research Institute-IMIM, Barcelona, Spain

${ }^{3}$ Institut de Neuropsiquiatria i Addiccions, Hospital del Mar. Parc de Salut Mar, Barcelona, Spain.

${ }^{4}$ Departament de Psiquiatria, Universitat Autònoma de Barcelona, Bellaterra, Spain

${ }^{5}$ Departament de Farmacologia, de Terapèutica i de Toxicologia, Universitat Autònoma de Barcelona,

Bellaterra, Spain

${ }^{6}$ Servei de Farmacología Clínica, Hospital Universitari Germans Trías i Pujol (IGTP), Badalona, Spain

*Correspondence to: mireia@energycontrol.org

Associació Benestar i Desenvolupament

Carrer Quevedo n²

08012 Barcelona, Spain.

$†$ Coauthors 
Emails:

Pol Quintana Mathé (polquintana@gmail.com)

Marc Grifell Guàrdia (marcgrifellguardia@gmail.com)

Liliana Galindo Guarín (liligalindo@gmail.com)

Ivan Fornís Espinosa (analisis@energycontrol.org)

Cristina Gil Lladanosa (crisgil91@gmail.com)

Xoán Carbón Mallol (xoancarbon@gmail.com)

Fernando Caudevilla Galligo (caudevilla@gmail.com)

Magí Farré Albaladejo (mfarre.germanstrias@gencat.cat)

Marta Torrens Melich (mtorrens@parcdesalutmar.cat) 


\section{The hidden web and the fentanyl problem: detection of ocfentanil as an adulterant of heroin}

Keywords: hidden web; dark web; ocfentanil; adulteration; heroin; fentanyl derivatives

Background

The popularization of anonymous markets such as Silk Road is challenging current drug policy and may provide a new context for old issues, such as adulteration of heroin with fentanyl derivatives. The aims of this paper are to report the presence of ocfentanil, a novel, potent, noncontrolled fentanyl analog, in samples sold as heroin in the hidden web, and to summarize the effects reported by users.

Methods

In 2015, four samples allegedly bought as heroin in cryptomarkets of the hidden web were sent to Energy Control for analysis. Energy Control is a Spanish harm reduction NGO that offers anonymous drug checking with the purpose of adapting counseling to the specific substances present in the drug and monitor the drug market. Identification was performed by GC/MS and 
LC/MS/MS. We contacted the submitters of the samples and performed an internet search to retrieve additional information.

Results

One sample contained ocfentanil, caffeine and heroin. Three samples contained the aforementioned substances plus paracetamol. Two out of the four contacted users reported distinct short acting, opioid-like effects. No fora discussion could be found about the effects of ocfentanil, neither web pages nor individuals advertising the substance.

\section{Conclusions}

We report the presence of a new substance detected in the hidden web as an adulterant of heroin, ocfentanil. It has short acting opioid-like effects, roughly the same potency as fentanyl, and can be injected, snorted or smoked. Severe side effects have been associated with its use, including one death. No discussion about this substance could be found in the internet, which suggests this substance has not been sold as such. Available data about purities of drugs purchased in cryptomarkets suggest that adulteration is not a severe problem and this agrees with users' perceptions. However, this study suggests that adulteration is a real threat not only at the street level, but also for users that buy substances in cryptomarkets, and suggest the need for harm reduction initiatives in this setting. 
The hidden web and the fentanyl problem: detection of ocfentanil as an adulterant of heroin

\section{INTRODUCTION}

During the last decade, the internet has posed two major challenges to the current drug policy. On the one hand, it has fostered the dissemination of New Psychoactive Substances (NPS), defined as "substances of abuse, either in a pure form or a preparation, that are not controlled by the 1961 Single Convention on Narcotic Drugs or the 1971 Convention on Psychotropic Substances, but which may pose a public health threat" (United Nations Office on Drugs and Crime, 2015). This implies that they can be distributed and sold under the label "not for human use", "research chemical", legal highs" or others, as they are not subject to world-wide law enforcement. Usually little to no scientific information is available about their effects or risks when they reach the market. It is worth noting that NPS sold in the internet are increasingly being used to adulterate controlled substances sold in conventional black markets (Gine, Espinosa, \& Vilamala, 2014; Hondebrink, Nugteren-van Lonkhuyzen, Van Der Gouwe, \& Brunt, 2015)

On the other hand, controlled substances can also be sold through the internet. The deep web can be defined as the internet content not accessible by traditional search engines, such as Google (Bergman, 2001). This ranges from email inboxes and university intranet, to networks such as Tor, which require specific software and configurations to be accessed. Tor allows both user and 
website anonymization, contributing to the existence of a subset of the deep web known as the hidden web, where illicit drugs can be bought and sold using websites known as cryptomarkets (anonymous markets). The product is paid using anonymous currencies such as BitCoin, and sent to the customer by conventional mail (Barratt, Ferris, \& Winstock, 2014). The most popular was Silk Road, launched in February 2011 and shut down by the FBI in October 2013 (Soska \& Christin, 2015). However, this operation has failed to stop the phenomenon and since then several other cryptomarkets have emerged, suggesting a high degree of resilience to disruptions (Soska \& Christin, 2015).

These new phenomena could transform long standing issues such as the presence of fentanyl derivatives in the drug market. Fentanyl is a synthetic opioid with analgesic and reinforcing effects. It has been used in medicine since 1986 and has several desirable qualities for anesthesiology and intensive care, such as: high potency (active doses start at $0.05 \mathrm{mg}$ ), rapid onset, and short duration of effects. Since its conception by Paul Janssen in the sixties, numerous derivatives have been synthesized and described in literature (hereinafter "fentanyls"). Some derivatives appeared at the end of the 1970's as designer drugs and produced epidemics of opiate overdoses and deaths (alpha-methylfentanyl, China white) (Buchanan and Brown, 1988). Ocfentanil is one of those derivatives: a potent, non-controlled fentanyl analog first described in a patent from 1986 (Bao-Shan Huang, Ross C. Terrell, Kirsten H. Deutsche, Linas V. Kudzma, \& Nhora L. Lalinde, 1986) and evaluated in humans in 1989 (code name A-3217) but never marketed. It exhibits analgesia and respiratory depression in a dose-related manner. Both effects 
peak at 6 minutes; analgesia largely disappears after one hour, while respiratory depression tends to last longer (Glass, 1989). Effects of $3 \mathrm{mcg} / \mathrm{kg}$ of ocfentanil are considered similar to those of $5 \mathrm{mcg} / \mathrm{kg}$ of fentanyl, with respect to cardiovascular response to tracheal intubation (Fletcher, Sebel, Murphy, Mick, \& Fein, 1991). Such potency poses a high risk of overdose if used recreationally, due to the difficulty to dose properly.

[Figure 3]

Unfortunately, some of the attributes that make these drugs valuable medicines are also responsible for their remarkable potential for abuse, dependence, and overdose. Misuse of fentanyls is a major and growing concern in several countries such as the USA (United States Drug Enforcement Administration, 2015) (Mercado-Crespo, Sumner, Spelke, Sugerman, \& Stanley, 2014), Canada (Fischer, Jones, Urbanoski, Skinner, \& Rehm, 2014), Australia (Roxburgh et al., 2013), and Estonia (European Monitoring Center for Drugs and Drug Addiction, 2014), where it is endemic. In the USA, fentanyl-related deaths have recently been shown to be on the rise (NDEWS, 2015). Communication of previously non-reported adverse effects of fentanyl illicit use, such as chest wall rigidity, may be related to its increase in availability and in intravenous route of administration (Burns et al., 2016). Reports about marketing through the conventional internet of non-controlled derivatives of fentanyl, such as butyrfentanil and 4-fluoro-butyrfentanil (Backberg, Beck, Jonsson, \& Helander, 2015), and the 
presence of acetylfentanyl and butyrfentanyl in cryptomarkets (Caudevilla et al., 2016), are especially disturbing due to the high harm associated with these substances (Mounteney, Giraudon, \& Denissov, 2015). Another worrying trend is the use of fentanyl derivatives to adulterate heroin, which started three decades ago (Buchanan \& Brown, 1988), and has persisted until today (Mounteney et al., 2015).

This case study features an old problem (adulteration of heroin with fentanyl derivatives) in a new context (the hidden web) with a novel substance (ocfentanil). The aims of this paper are to report the presence of ocfentanil in samples sold as heroin in the hidden web, summarize the effects reported by users, and discuss the implications of these findings.

\section{METHODS}

\section{Collection of samples}

For this study, we selected all heroin samples allegedly bought from the hidden web and submitted by users to a Spanish non-governmental organization (NGO) for analysis, whose chemical composition contained ocfentanil. Energy Control is a harm reduction project belonging to the NGO “Asociación Bienestar y Desarrollo." Energy Control's aim is to provide information and counselling to people who intend to consume drugs. Energy Control offers a 
free and anonymous drug checking service to Spanish nationals and charges a fee for international samples. Spanish nationals can bring their samples to one of the 4 Energy Control headquarters (Madrid, Catalonia, Balearic Islands and Andalucía), send them by mail, or submit them during outreach work in nightlife settings, such as music festivals, clubs, and underground raves. Energy Control's drug checking service has a three-fold purpose: 1) make contact with drug users that would not normally approach drug programs and which are usually concerned with how the consumption, adulteration, and purity of their products affect their health; 2) use this service as an educational and harm/risk reduction tool by getting in touch with consumers and providing them with individual and personalized information about the substance they may consume; 3) monitor the illegal market detecting new trends of drugs and drugs use and make this information available to all stakeholders involved. Additionally, analysis of both national and international samples received, although not being an exact reflection of the market, contributes to our understanding of what is happening at the street level.

As ocfentanil was being detected, the result was sent to the users who submitted the sample, along with a warning about the risks of this adulteration. Later on, at the time of preparing this study, we recovered the data related to these analysis, and we contacted the same users again to gather more information about the substance, its effects where was it bought, what was the nickname of the seller, etc. Consent was gathered from them to publish this information. 
Laboratory analysis

Sample preliminary identification was performed by gas chromatography coupled to mass spectrometry (GC/MS) using an Agilent 7890B gas Chromatograph, coupled to a 5977A quadrupole mass spectrometer detector (Agilent; Santa Clara, CA, USA). The gas chromatograph was fitted with G4513A auto sampler injector. Insert liners packed with silanized glasswool were used, and the injector and the interface were operated at 280 C. Samples were injected in split mode into a $30 \mathrm{~m} 0.25 \mathrm{~mm}$ i.d., $0.25 \mu \mathrm{m}$ film thickness $5 \%$ phenylmethylsilicone column (HP-5MS, Agilent Technologies). Helium was used as carrier gas at a flow rate of 1 $\mathrm{mL} / \mathrm{min}$. The oven temperature was initially maintained at $90 \mathrm{C}$ for 2 min and programmed to reach $320 \mathrm{C}$ at $20 \mathrm{C}$ per min. It was finally maintained at $320 \mathrm{C}$ for $9.5 \mathrm{~min}$ (total run time was $21.5 \mathrm{~min})$. The mass spectrometer was operated in electron impact ionization mode at $70 \mathrm{eV}$. In order to confirm the mass spectra, four libraries were used: the Searchable Mass Spectral Library NIST/EPA/NIH Mass Spectral Library, Data Version: NIST 14; Searchable Mass Spectral Library Version 2.3 (http://www.swgdrug.org/ms.htm), Searchable Mass Spectral Library Cayman Spectral Library

(https://www.caymanchem.com/app/template/SpectralLibrary.vm) and Energy Control's internal mass spectral library.

Confirmation was performed by liquid chromatography coupled to tandem mass spectrometry (LC/MS/MS) using an Agilent 1100 series, HPLC chromatograph (Agilent technologies, Palo 
Alto, USA) and an Esquire 3000 plus mass spectrometer MRM (Bruker Daltonic GmBh, Bremen, Germany). Chromatography was performed using a Poroshell 120 EC-C18 column (100-mm length $\times 2.1 \mathrm{~mm}$ i.d., $2,7 \mu \mathrm{m}$ particle size) at $30{ }^{\circ} \mathrm{C}$. The mobile phases consisted of $1 \%$ formic acid (A) and 1\% formic acid in methanol (B). The following gradient elution was used: at time $0 \mathrm{~min} 15 \% \mathrm{~B}$ changed to $90 \% \mathrm{~B}$ in $7 \mathrm{~min}$, held for $1 \mathrm{~min}$, changed back to the initial conditions in $1 \mathrm{~min}$. Before injection of the next sample the column was allowed to re-equilibrate during $7 \mathrm{~min}$. The flow rate was $0.35 \mathrm{~mL} / \mathrm{min}$. The electrospray source $(\mathrm{ESI})$ was operated in the positive ionization mode. Product ions that were obtained by collision-induced dissociation allowed the MS/MS to be operated in the multiple reaction monitoring (MRM) mode. The MRM transition was 371 (precursor ion) to 188 (product ion). The dwell time was set at $0.25 \mathrm{~s}$. The desolvation gas was nitrogen set at $365{ }^{\circ} \mathrm{C}$ and delivered at a flow rate of $9 \mathrm{~L} / \mathrm{min}$. The capillary voltage was $3.90 \mathrm{kV}$, and the collision gas was helium. Bruker Compass Hystar system software Version 3.2-SR2 was used for instrument control and identification.

\section{Literature and fora research}

Systematic searches on the surface internet were conducted in December 2015 in English, French and Spanish, using "ocfentanil", "ocfentanyl" and "A-3217" in Google search engine. The hidden web was searched using Grams search engine (http://grams7enufi7jmdl.onion). Internal searches were conducted in Alphabay, Outlaw and Dream marketplace. Google trends was also 
used searching "ocfentanil". A search was also conducted in Pubmed, Google Scholar and Google Trends using the same criteria.

\section{RESULTS}

Analysis of samples

A total of four samples were analyzed. Samples \#1 and \#4 were sent by Spanish nationals. Sample \#2 and \#3 were submitted via Techno Plus, a French harm reduction NGO, upon notice of unusual effects. Results are described in table 1. GC/MS and LC/MS/MS spectra are shown on figures 1 and 2. Quantification of ocfentanil was not possible due to the lack of analytical standards.

[TABLE 1]

[FIGURE 1]

[FIGURE 2]

Effects reported by users 
Contact was successfully established with three users in collaboration with Techno Plus. User from sample \#1 did not try the mixture both before and after sending it for analysis. User from sample \#4 reported analgesia and nausea, but could not be contacted for further information. Users from sample \#2 and \#3 did try the substances before sending it for analysis, and reported the following:

"It's a hard effect, like very very strong heroin (something around 40\%), coming very quick (3min after snorting), short (maybe 15-20 min of real buzz), and 1 big hour of small effect."

"The effect is opiate of course, but not exactly like heroin: more "stimulant", less cool and euphoric. It seems that many people don't see the difference, for example a friend of mine didn't trust me, he was sure that it was great heroin. This point is important: only few people have tried real pure heroin so they can easily imagine that there is a difference (I tried medical heroin and I can say it: the effects are exactly the same as street heroin, just less strong!)”

"For really addicted people there is a difference: the effect is shorter so they are sooner in withdrawal: one person said what alerted him was that when he took this heroin, he was in withdrawal every morning when he woke up." 
No reports from users claiming to have tested ocfentanil either alone or intentionally could be found.

Supply and presence on the internet

The majority of information that was found on the internet and the hidden web about ocfentanil was related to its use as an adulterant of heroin.

One post on a well-known internet forum on July 2015 mentions two samples sold as heroin by a cryptomarket web seller, "FrenchConnection". The user claimed that in fact, both samples contained a mixture of paracetamol, caffeine and ocfentanil, based on the results of colorimetric tests and qualitative analysis with GC/MS. In connection with this, users from samples \#2 and \#3 reported:

SWIM (author's note: acronym for Someone Who Is not Me, used in fora where the possibility of auto incrimination is perceived as a real threat) buy some heroin $\left(n^{\circ} 3\right.$, called " $\left.A+++"\right)$ from Europdrugs in the beginning of September for the second time (first was ok). "The effect was strong but strange: more stimulant and less euphoric and first of all very short (3h!), which was surprising for a strong product." 
"Yesterday I surfed on a French drugs forum and saw a post from one person who bought the same heroin from the same vendor at the same time (05/09) and got exactly the same effects. He said that the short time of effects was incredible with withdrawal symptoms coming only a night after use (which was the first time of his heroin user's life)."

Two other persons confirmed this on the forum, saying quite the same story and another said the same about another big french seller: frenchconnection. Finally, one of them contacted the seller who did not denied but was (or acted as he was) surprised and worried about this and gave the money back to the customer who did not post a bad feedback."

"Europedrugs was a good heroin seller, so I think it was just a bad batch (we already bought another sample to see what he sells now)"

Harm reduction organizations such as Techno+ issued an alert to notify cryptomarket customers and the drug users' community, after which other buyers claimed to have had similar experiences with the mentioned sellers. This information was shared and discussed in at least 6 fora from surface internet, including the well-known bluelight and drugs-forum, social networks such as facebook, as well as hidden web fora such as Alphabay. 12,941 views were counted from the pages in which this information was available at the time of writing. Other results were related to 
media coverage following the deaths in Belgium and warnings from harm reduction and institutional organizations.

No web pages or individuals advertising ocfentanil could be found on the surface internet or on any of the main hidden web marketplaces. Google Trends' query returned a "Not enough search volume to show graphs" message.

\section{DISCUSSION}

In this paper we report the presence of a new substance detected in the hidden web, ocfentanil, as well as a summary of the effects reported by users. It is not the first time A British harm reduction organization, WEDINOS, also reported the presence of ocfentanil, paracetamol and caffeine in samples submitted for analysis between March and July 2015 (Wedinos, 2015), which is concordant with our findings. Users reported snorting and/or smoking the substance, experiencing typical opiate-like effects such as euphoria, relaxation and nausea. Other reported effects (chest pain, psychosis and agitation) were not described in published clinical trials and may indicate a high potential for toxicity, although this information should be taken with caution because other substances may have been involved. Moreover, one fatality due to ocfentanil 
consumption has recently been confirmed. In March 2015, a Belgium citizen was found dead at his home after presumably snorting a brown powder bought off a cryptomarket that contained ocfentanil, caffeine and paracetamol (Coopman et al., 2016).

No advertisements or discussion about trip reports could be found on the web, which suggests this substance has not been sold as such at the time of writing this article. Therefore, we hypothesize that its introduction into the market was done by one unique person or group, which did not consider selling the compound through the usual NPS and "legal highs" internet channels.

Selling fentanyl derivatives as heroin has been happening for the last few years on the streets and is considered a growing trend (Mounteney et al., 2015); it now seems to have reached cryptomarkets, where previous research has suggested that the purity may be higher and the adulteration lower than traditional markets (Barratt et al., 2014; Caudevilla et al., 2016). Up to now, overdose outbreaks caused by heroin adulterated with fentanyls have been circumscribed to geographical locations, and it was feasible to disrupt distribution and control damage. But if this trend extends to heroin sold in the dark web, outbreaks might scatter all over the world, which will pose new challenges to what is already a difficult matter. Information about adulteration (including results of one analysis performed by an individual) was shared within this virtual community as a harm reduction strategy, a phenomenon that has been described by others (Van Hout \& Bingham, 2013). In this context, we hypothesize that offering drug testing in online 
marketplaces, might be an effective way to minimize consumption of drugs adulterated with high-risk substances, such as ocfentanil. The alert reporting heroin-adulterated ocfentanil, launched by Energy Control, quickly spread through drug fora and websites related with harm reduction, in both the surface web and the Deep Web (DNM avengers, URL:http://avengerfxkkmt2a6.onion/ and The Hub, URL: http://thehub7gqe43miyc.onion/). In just four days, this information became available in English ("deepdotweb.com", "Psychonaut.com”,"Bluelight.com."), French ("Psychoactif.org."), German ("Eve-rave.ch."), Swedish ("Svenskabrukarforeningen.se.") and Polish ("Hyperreal.info."). Discussions on these fora pointed to two specific vendors (FRENCHCONNECTION and EuropeDrugs) as the source of the adulteration, and both vendors were eventually banned from two of the main Deep Web marketplaces (Alphabay and Nucleus). Data provided to Energy Control by users that submitted the samples reported in this paper is also linked to these vendors, but the original source of samples could not be confirmed. Therefore, the identity of the alleged vendors was not mentioned in the alert and its influence in supply could not be measured, even though data from fora suggests it might have impacted supply. In any case, it is a reminder that adulteration is indeed a real risk in the Deep Web. Moreover, as new fentanyl derivatives will certainly emerge in the near future, monitoring systems based on drug testing may be of vital importance to react in a timely manner, as warnings issued in this case were published and discussed within the drug users' internet community (EMCDDA, 2016). 
This study has several limitations. First, specific quantification of ocfentanil was not possible due to lack of analytical standards. Secondly, the scarcity of users $(n=4)$ that reported trying the substance and the fact that they all ingested a mixture of two active opiates, (ocfentanil and heroin) limit generalizations about the nature of its effects. Nevertheless, the presence of ocfentanil was analytically confirmed, therefore yielding the first two published reports on the effects of ocfentanil consumed recreationally. Considering all this, and given the lack of available information about this substance, the authors felt these findings were worth publishing notwithstanding the mentioned limitations.

We conclude that ocfentanil is a substance with short acting opioid-like effects, roughly the same potency as fentanyl, and that can be injected, snorted, or smoked. Users reported a product less euphoric than heroin, which is in concordance with other studies that report that the fentanyl "high" does not meet users' expectations when compared with other opioids (La Barbera, M., 1983). Severe side effects have been associated with its use, which contrasts with the good safety profile exhibited in clinical trials. This is similar to the use of other fentanyls, which are considered safe in clinical settings but are associated with high levels of harm in recreational settings. This indicates that side effects probably depend more on the context of use rather than in the substance itself, which suggests harm reduction implementations might be as useful as with other opiates. 
Several questions remain: is the extension of this phenomenon to the hidden web a sign that the fentanyls problem is growing? What was the drive that led to using ocfentanil as an adulterant, instead of other already marketed fentanyl derivatives such as butyrfentanyl or acetylfentanyl? As ocfentanil is not a world-wide controlled substance, why was it not sold as a legal high in the first place? Trying to answer these questions might lead to new insights and, in the long term improve our understanding of the phenomenon of New Psychoactive Substances and its relationship with the internet.

\section{CONFLICT OF INTEREST}

The authors report no conflict of interest.

\section{ACKNOWLEDGMENTS}

We would like to express our gratitude to Rafael de la Torre of the Institute of Medical Investigations of Hospital del Mar of Barcelona (IMIM), the time and dedication of all of Energy

Control's volunteers and the trust drug users put in us. We also would like to thank Vincent from Techno+, for his critical help in contacting the users that ingested two of the analyzed samples.

Supported in part by grants of Instituto de Salud Carlos III-FEDER (RTA RD12/0028/0009), and The European Commission (Drug Prevention and Information Programme 2014-16, contract no.: JUST/ 2013/DPIP/AG/4823, EU-MADNESS project). Liliana Galindo is a Rio Hortega fellowship (ISC-III; CM14/00111). 


\section{BIBLIOGRAPHY}

Backberg, M., Beck, O., Jonsson, K. H., \& Helander, A. (2015). Opioid intoxications involving butyrfentanyl, 4-fluorobutyrfentanyl, and fentanyl from the Swedish STRIDA project. Clinical Toxicology, 53(7), 609-617. http://doi.org/10.3109/15563650.2015.1054505

Bao-Shan Huang, E., Ross C. Terrell, C., Kirsten H. Deutsche, M., Linas V. Kudzma, N. B., \& Nhora L. Lalinde, W. N. (1986). N-Aryl-N-(4-Piperidinyl)Amides and pharmaceutical compositions and methods employing such compounds. United States of America.

Barratt, M. J., Ferris, J. A., \& Winstock, A. R. (2014). Use of Silk Road, the online drug marketplace, in the United Kingdom, Australia and the United States. Addiction, 109(5), 774-783. http://doi.org/10.1111/add.12470

Bergman, M. K. (2001). The Deep Web: surfacing hidden value. Journal of Electronic Publishing, 7(1). http://doi.org/http://dx.doi.org/10.3998/3336451.0007.104

Bluelight.com. Warning Deep Web Ocfentanyl cutting heroin. Retrieved 18th of August 2016 from: http://www.bluelight.org/vb/threads/772520-WARNING-DEEP-WEB-Ocfentanyl-cuttinghero\% $3 \% \mathrm{AFn}$

Buchanan, J. F., \& Brown, C. R. (1988). "Designer drugs". A problem in clinical toxicology. Medical Toxicology, 3(1), 1-17.

Burns, G., DeRienz, R.T., Baker, D.D., Casavant, M., Spiller, H.A., 2016. Could chest wall 
rigidity be a factor in rapid death from illicit fentanyl abuse? Clinical Toxicology, 54, 420423. doi:10.3109/15563650.2016.1157722

Caudevilla, F., Ventura, M., Fornís, I., Barratt, M.J., Vidal, C., Lladanosa, C.G., Quintana, P., Muñoz, A., Calzada, N, 2016. Results of an international drug testing service for cryptomarket users. International. Journal of Drug Policy, In press. doi:10.1016/j.drugpo.2016.04.017

Coopman, V., Cordonnier, J., De Leeuw, M., Cirimele, V., 2016. Ocfentanil overdose fatality in the recreational drug scene. Forensic Science Internacional 266, 469-473. doi:10.1016/j.forsciint.2016.07.005

Deepdotweb.com. Warning: Fentanyl Being Sold as Heroin in DNMS. Retrieved 18th of August 2016 from: https://www.deepdotweb.com/2015/10/17/warning-fentanyl-being-sold-as$\underline{\text { heroin/ }}$

European Monitoring Center for Drugs and Drug Addiction. (2014). Drugnet Europe 85. Lisbon.

European Monitoring Center for Drugs and Drug Addiction. (2016). European Drug Report. Trends and Developments 2015. doi:10.2810/88175

Eve-rave.ch. Warnung: Fentanyl als H über DNM vertickt. Retrieved $18^{\text {th }}$ of August 2016 from: http://www.eve-rave.ch/Forum/viewtopic.php?t=43312

Fischer, B., Jones, W., Urbanoski, K., Skinner, R., \& Rehm, J. (2014). Correlations between prescription opioid analgesic dispensing levels and related mortality and morbidity in 
Ontario, Canada, 2005-2011. Drug and Alcohol Review, 33(1), 19-26. Retrieved from http://www.ncbi.nlm.nih.gov/pubmed/24261474

Fletcher, J. E., Sebel, P. S., Murphy, M. R., Mick, S. A., \& Fein, S. (1991). Comparison of ocfentanil and fentanyl as supplements to general anesthesia. Anesth Analg, 73(5), 622-626.

Gine, C. V, Espinosa, I. F., \& Vilamala, M. V. (2014). New psychoactive substances as adulterants of controlled drugs. A worrying phenomenon? Drug Test Anal, 6(7-8), 819-824. http://doi.org/10.1002/dta.1610

Hondebrink, L., Nugteren-van Lonkhuyzen, J. J., Van Der Gouwe, D., \& Brunt, T. M. (2015). Monitoring new psychoactive substances (NPS) in The Netherlands: data from the drug market and the Poisons Information Centre. Drug and Alcohol Dependence, 147, 109-15.

Hyperreal.info. UWAGA: fentanyl i jego pochodne sprzedawane jako heroina w darkmarketach Retrieved $18^{\text {th }}$ of August 2016 from: https://hyperreal.info/news/uwaga-fentanyl-i-jegopochodne-sprzedawane-jako-heroina-w-darkmarketach

La Barbera, M., W. T. (1983). Characteristics, attitudes and implications of fentanyl use based on reports from self-identified fentanyl users. Journal of Psychoactive Drugs, 15(4), 293301.

Mercado-Crespo, M. C., Sumner, S. A., Spelke, M. B., Sugerman, D. E., \& Stanley, C. (2014). Notes from the field: increase in fentanyl-related overdose deaths - Rhode Island, November 2013-March 2014. MMWR. Morbidity and Mortality Weekly Report, 63(24), 531. 
Mounteney, J., Giraudon, I., \& Denissov, G. (2015). Fentanyls: are we missing the signs? Highly potent and on the rise in Europe. International Journal of Drug Policy, 26(7), 626-631. http://doi.org/10.1016/j.jhazmat.2013.02.017

NDEWS, 2015. NDEWS Special Report: Fentanyl 1-21. Retrieved August 5, 2016, from http://www.ndews.org/sites/ndews.umd.edu/files/NDEWSSpecialReportFentanyl12072015. pdf

Psychoactif.org. Héro coupée à l'ocfentanyl sur le deep web. Retrieved $18^{\text {th }}$ of August 2016 from: https://www.psychoactif.org/forum/t16265-p1-Hero-coupee-ocfentanyl-sur-deepweb.html

Psychonaut.com. Ocfentanyl cutting heroin on deep web. Retrieved $18^{\text {th }}$ of August 2016 from: http://www.psychonaut.com/harm-reduction/56966-ocfentanyl-cutting-heroin-deepweb.html

Roxburgh, A., Burns, L., Drummer, O. H., Pilgrim, J., Farrell, M., \& Degenhardt, L. (2013). Trends in fentanyl prescriptions and fentanyl-related mortality in Australia. Drug and Alcohol Review, 32(3), 269-75.

Soska, K., \& Christin, N. (2015). Measuring the Longitudinal Evolution of the Online Anonymous Marketplace Ecosystem. Proceedings of the 24th USENIX Security Symposium, (August), 33-48.

Svenskabrukarforeningen.se. Fentanyl säljs som heroin på nätet. Retrieved $18^{\text {th }}$ of August 2016 from: http://www.svenskabrukarforeningen.se/node/7496

United Nations Office on Drugs and Crime. (2015). The challenge of new psychoactive substances. Retrieved from http://www.unodc.org/documents/scientific/NPS_Report.pdf

United States Drug Enforcement Administration. (2015). DEA Issues Nationwide Alert on 
Fentanyl as Threat to Health and Public Safety. Retrieved December 5, 2015, from http://www.dea.gov/divisions/hq/2015/hq031815.shtml

Van Hout, M. C., \& Bingham, T. (2013). "Silk Road", the virtual drug marketplace: A single case study of user experiences. International Journal of Drug Policy, 24(5), 385-391. http://doi.org/10.1016/j.drugpo.2013.01.005

Wedinos. (2015). Wedinos Newsletter $n^{\circ} 6$. Retrieved from http://www.wedinos.org/resources/downloads/Philtre_Issue_6.pdf 


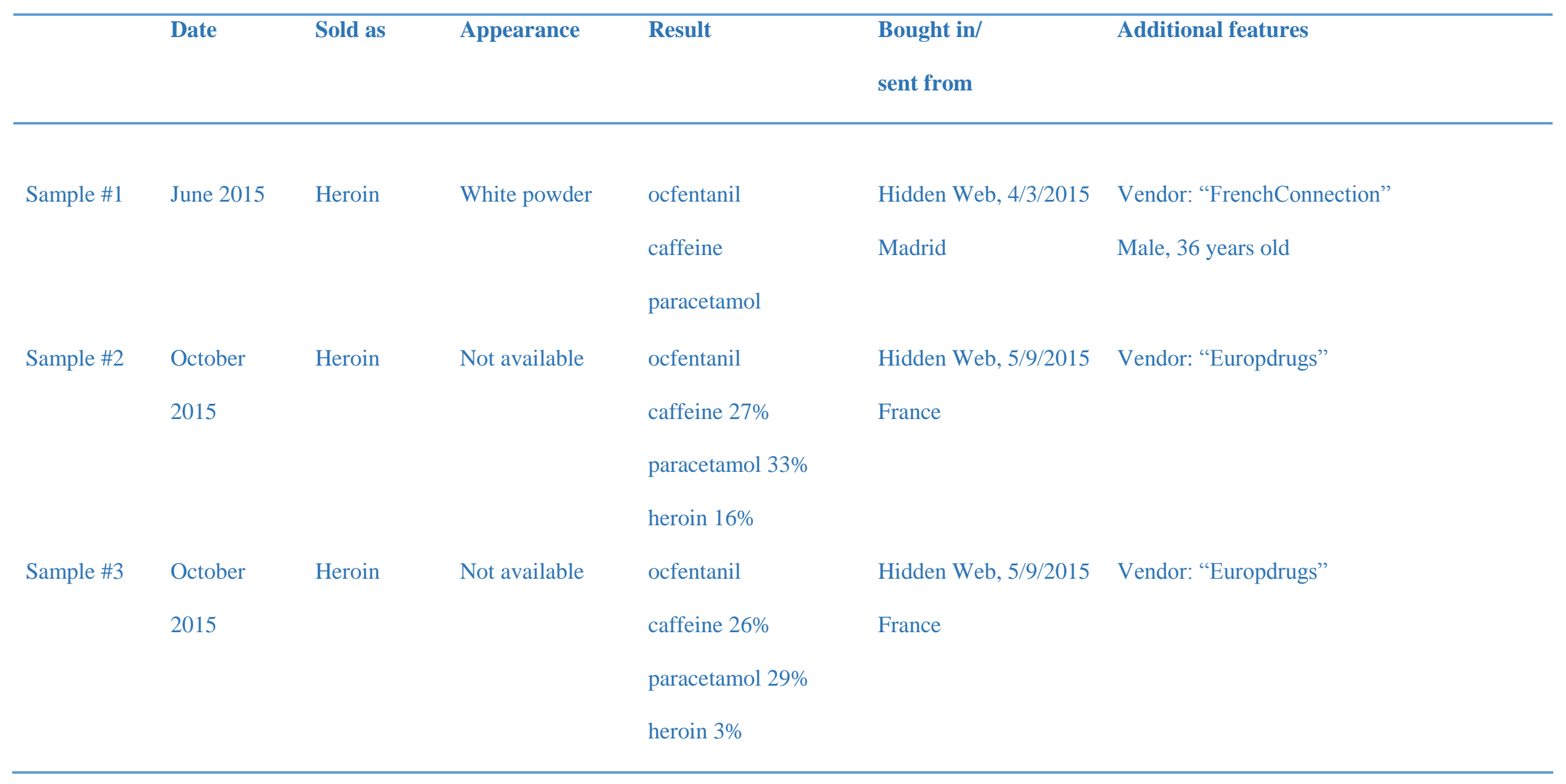




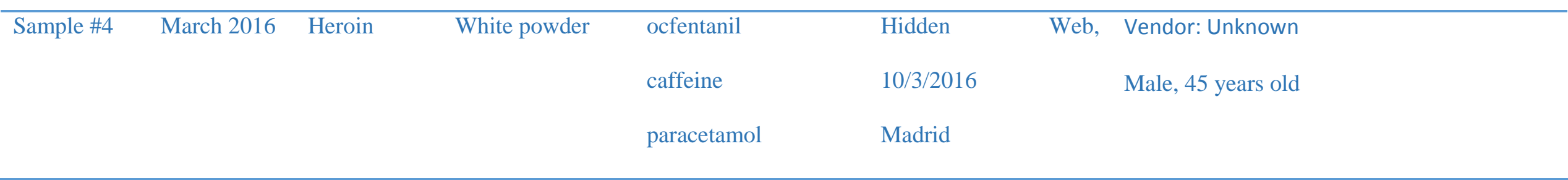

Table 1: Description of the samples submitted to Energy Control 

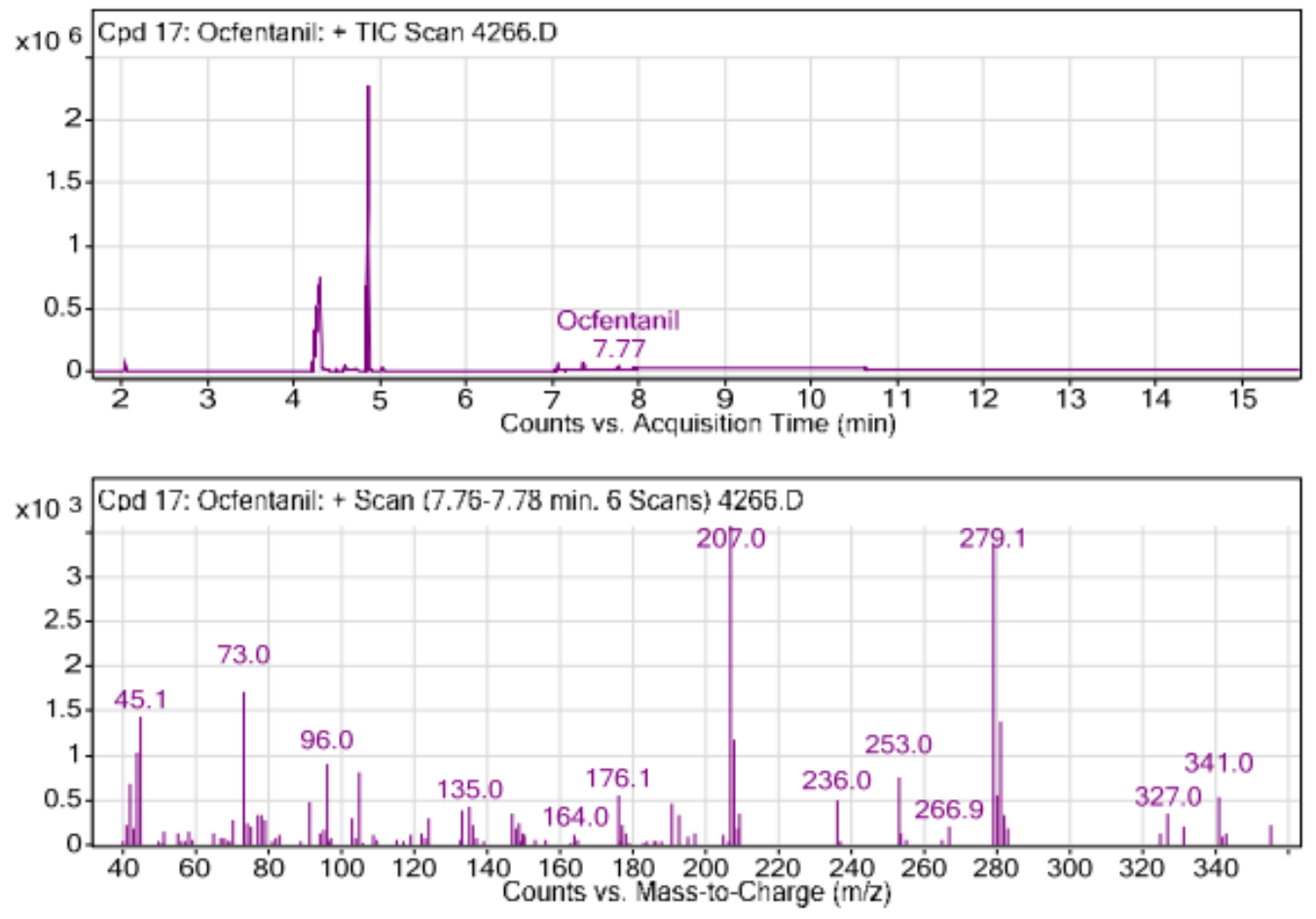

Figure 1: Results of GC/MS. Upper panel shows total ion chromatogram of sample \#2 and lower panel shows mass spectra of ocfentanil. 


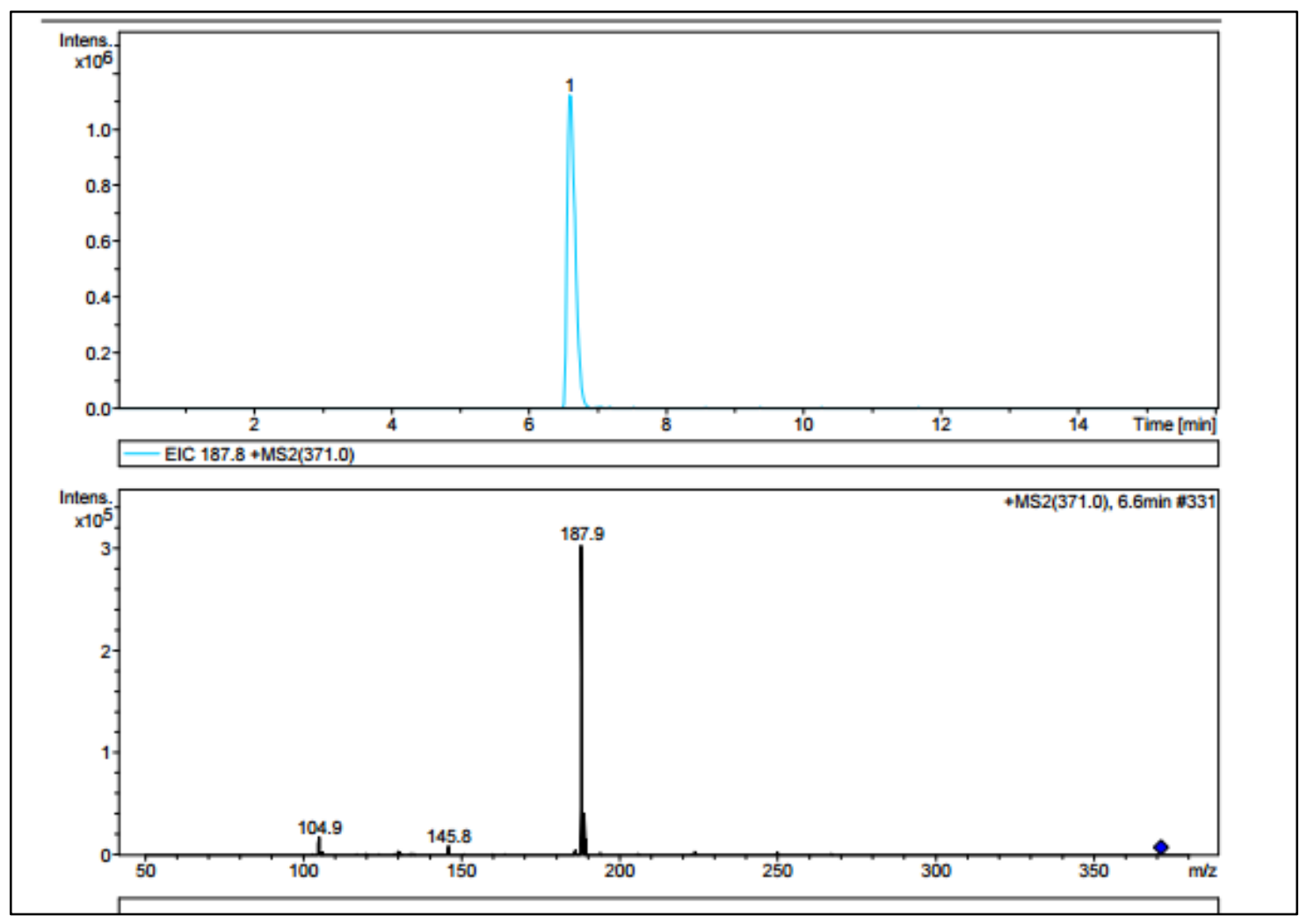

Figure 2: Results of ocfentanil using LC/MS/MS with an ion trap in MRM mode 


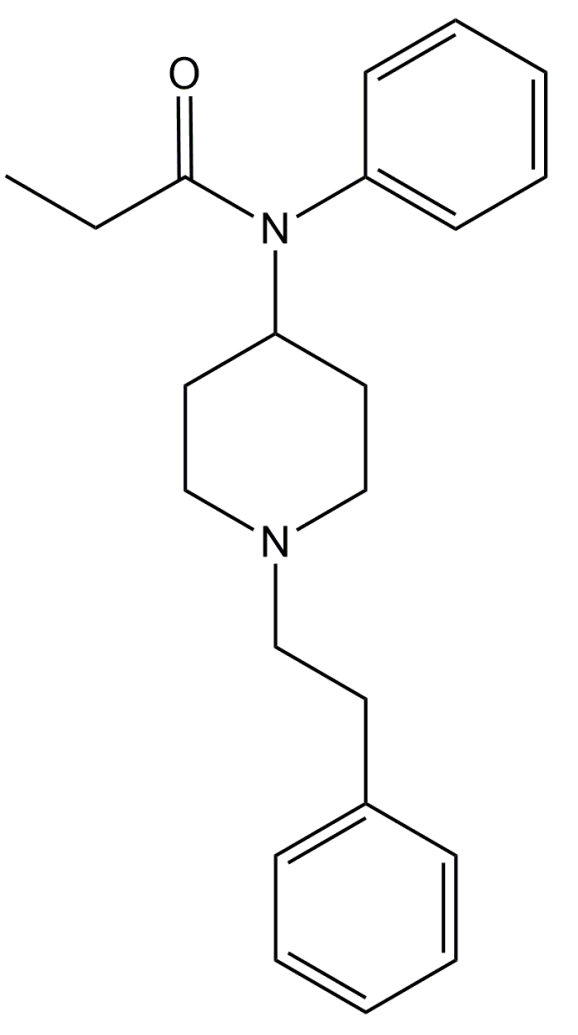

Fentanyl

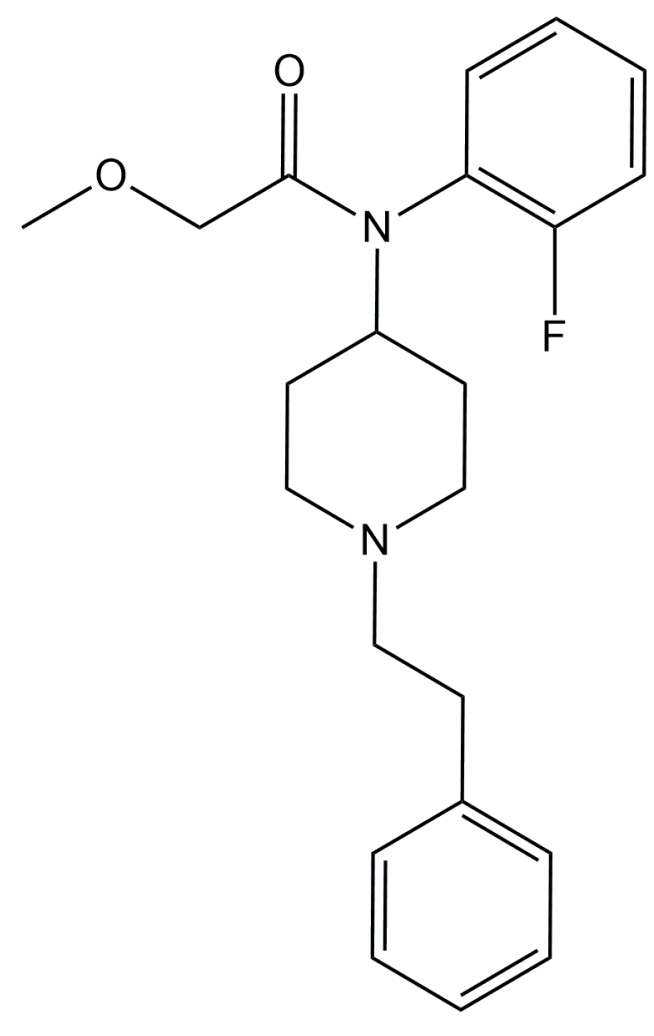

Ocfentanil

Figure 3 